\title{
In vitro Interaction of Metformin with Diclofenac in Aqueous Medium
}

\section{Shuvashis Saha ${ }^{1}$, Rehana Begum ${ }^{1}$, Md. Zakir Sultan ${ }^{2}$, Farhad Md. Amjad ${ }^{3}$, Md. Shah Amran ${ }^{1}$ and Md. Amjad Hossain ${ }^{1}$}

\author{
${ }^{1}$ Department of Pharmaceutical Chemistry, Faculty of Pharmacy, University of Dhaka, Dhaka-1000, \\ Bangladesh \\ ${ }^{2}$ Centre for Advanced Research in Sciences (CARS), University of Dhaka, Dhaka-1000, Bangladesh \\ ${ }^{3}$ Dhaka Medical College, Dhaka-1000, Bangladesh
}

\begin{abstract}
Combination therapy may be unavoidable and common way for the treatment of disease where two or more drugs are given concurrently. The drugs may exhibit effects independently or may interfere with each other. Metformin is an anti-diabetic drug and diclofenac is a NSAID. The in vitro interaction of metformin with diclofenac was studied at room temperature and at different $\mathrm{pH}$ conditions. The studies were performed by various UV-Visible spectrophotometric, conductometric and HPLC methods. It was found that metformin formed stable 1:1 complex with diclofenac. The interaction may greatly influence the activity of these molecules.
\end{abstract}

Key words: Metformin, Diclofenac, interaction.

\section{INTRODUCTION}

After receiving the drug orally, it must be dissolved in the GI fluids and then absorption occurs through the membrane into the systemic circulation. The drug is distributed to various parts of the body where it may be stored, metabolized, exert a pharmacological action and excreted. Thus, a drug may come in close contact with foodstuffs and different body components or with other drugs inside the body and it may form a complex with such a species. The area of drug interaction involves and correlates all the disciplines of drug management and health care system relevant to the contemporary practice of medicine. ${ }^{1-3}$

Knowledge of drug interaction may allow early recognition and prevention of adverse consequences. The most comprehensive understanding of clinically significant drug interaction can be achieved by combining knowledge of the mechanism of drug interaction with recognition of the high-risk patients and the identification of drug with a narrow therapeutic index. Problem arising from the interaction of drugs may be overcome by partial

Correspondence to: Md. Amjad Hossain

E-mail: amranms@du.ac.bd

Dhaka Univ. J. Pharm. Sci. 11(2): 101-106, 2012 (December) changes in the molecular pattern, by blocking the reactive site in the molecule, by changing the dosage regimen or by avoiding the combined application of interacting drugs. However, to take any step to manage the interaction problems, the nature of interaction should be known. We should know the possible interaction of a new drug prior to use clinically. For the drugs which are being used conventionally, interaction studies are also very important to detect the problems yet to be found out. ${ }^{4}$

The principal purpose of the present study was to investigate complex formation and to study the nature and strength of complex which could be due to interaction of metformin with diclofenac. Metformin is an anti-diabetic drug. It is the first-line drug of choice for the treatment of type- 2 diabetes, particularly in overweight and obese people and those with normal kidney function. Its mode of action is thought to be multifactoral and includes delayed uptake of glucose from the intestinal tract, increased peripheral glucose utilization mediated by increased insulin sensitivity and inhibition of increased hepatic and renal gluconeogenesis. On the other hand, diclofenac is a NSAID. It is commonly used for the reduction of pain, fever, inflammation and stiffness caused by conditions such as osteoarthritis, kidney 
stones, rheumatoid arthritis, psoriatic arthritis, gout, ankylosing spondylitis, tendonitis and the treatment of primary dysmenorrhea. It works by inhibiting both the COX-1 and COX-2 enzymes. ${ }^{5}$

\section{MATERIALS AND METHODS}

Drugs and chemicals. The working standard of diclofenac sodium (potency: $98.70 \%$ ) was a gift from Square Pharmaceuticals Ltd., Dhaka, Bangladesh. The working standard of metformin (potency: 99.27\%) was obtained from Beximco Pharma Ltd., Dhaka, Bangladesh. Hydrochloric acid (37\%), potassium chloride, orthophosphoric acid, sodium hydroxide, potassium hydroxide, potassium dihydrogen orthophosphate, disodium hydrogen orthophosphate, methanol, ethanol were of analytical grade and purchased from the local suppliers.

\section{Preparation of buffer solutions ${ }^{6,7}$}

pH 1.4. This buffer was prepared by dissolving $6.57 \mathrm{~g}$ of potassium chloride in demineralized water and added $119.0 \mathrm{ml}$ of $0.1 \mathrm{M}$ hydrochloric acid. Then the volume was made up to $1000 \mathrm{ml}$ with the same solvent. $\mathrm{pH}$ was adjusted to 1.4 with hydrochloric acid. $250 \mathrm{~mL}$ of $0.1 \mathrm{M}$ hydrochloric acid was prepared by mixing $2.25 \mathrm{ml}$ of $37 \%$ hydrochloric acid with demineralized water.

pH 2.4. This buffer was prepared by mixing 6.7 $\mathrm{ml}$ of orthophosphoric acid with $50.0 \mathrm{ml}$ of $4 \% \mathrm{v} / \mathrm{v}$ solution of $2 \mathrm{M}$ sodium hydroxide and diluted to 1000 $\mathrm{mL}$ with demineralized water. $\mathrm{pH}$ was adjusted to 2.4 with sodium hydroxide. $100 \mathrm{ml}$ of $2 \mathrm{M}$ sodium hydroxide was prepared by dissolving $8.0 \mathrm{~g}$ of sodium hydroxide in demineralized water. $100.0 \mathrm{ml}$ of $4 \%$ $\mathrm{v} / \mathrm{v}$ solution of $2 \mathrm{M}$ sodium hydroxide was prepared by diluting $4 \mathrm{ml}$ of $2 \mathrm{M}$ sodium hydroxide to $100 \mathrm{ml}$ with demineralized water.

pH 7.4. This buffer was prepared by mixing 65.4 $\mathrm{mL}$ of $0.02 \mathrm{M}$ potassium dihydrogen orthophosphate with $289.7 \mathrm{ml}$ of $0.01 \mathrm{M}$ disodium hydrogen orthophosphate and diluted to $1000 \mathrm{ml}$ with demineralized water. $100 \mathrm{ml}$ of $0.02 \mathrm{M}$ potassium dihydrogen orthophosphate was prepared by dissolving $0.2722 \mathrm{~g}$ of potassium dihydrogen orthophosphate in demineralized water and the final volume up to $100 \mathrm{ml} .500 \mathrm{ml}$ of $0.01 \mathrm{M}$ disodium hydrogen orthophosphate was prepared by dissolving $0.710 \mathrm{~g}$ of disodium hydrogen orthophosphate in demineralized water.

\section{Preparation of stock solutions}

Metformin. $100 \mathrm{ml}$ stock solution of $1 \times 10^{-3} \mathrm{M}$ was prepared by dissolving $0.0129 \mathrm{~g}$ of metformin in demineralized water and 1-2 drops of conc. hydrochloric acid was added to dissolve it and finally made the volume was made up to $100 \mathrm{ml}$ with the same solvent. The stock solution was diluted to the desired strength by buffer solutions.

Diclofenac. $100 \mathrm{ml}$ stock solution of $1 \times 10^{-3} \mathrm{M}$ was prepared by dissolving $0.038 \mathrm{~g}$ of diclofenac in demineralized water and added 1-2 drops of conc. hydrochloric acid to dissolve it and finally the volume was made up to $100 \mathrm{ml}$ with the same solvent. The stock solution was diluted to the desired strength by buffer solutions.

Drug-drug interaction analysis by observation of absorption spectra. In this procedure, the ultraviolet absorption characteristics of metformin, diclofenac and their 1:1 mixture in solution at different $\mathrm{pHs}$ were compared. The concentrations of samples were kept at very dilute levels in each case and the measurements were made using an UVvisible spectrometer (UV-1601, Shimadzu, Japan) equipped with computer and appropriate software program. The stock solutions of the sample were diluted to appropriate levels by buffer of the desired $\mathrm{pH}$ and the spectra were recorded between 200-400 nm.

Drug-drug interaction analysis by Job's method of continuous variations. Job's spectroscopic method of continuous variation plots was carried out to confirm the formation of 1:1 complex between the drugs to be studied. In this method, solutions of different concentrations of metformin and diclofenac were prepared using solvent and a continuous variation plots were made by corrected absorbance against the volume fraction of one reactant.

Drug-drug interaction analysis by conductometric titration method. Conductance is an inherent 
property of an ionic species. The conductance of species may change in solution due to the interaction with other species. In this method, conductance was changed due to the function of varying molar ratios of the species in a mixture. Conductometric titrations in demineralized water system at $\mathrm{pH} 7.4$ were carried out using a Conductometer (Jenway, Switzerland) to find the molar ratios at which complexation occurred. $35 \mathrm{~mL}$ of $0.05 \mathrm{M}$ solution of metformin was taken in a $100 \mathrm{~mL}$ beaker and was titrated individually with gradual addition of $0.05 \mathrm{M}$ solution of diclofenac from a burette. Two titrations were carried out; one was titrated against the other and vice-versa. The conductance at each addition was recorded. Then the conductance was plotted against the molar ratios of the titrants to obtain the conductivity curves. The titration curve showed break at the points of possible interaction.

Drug-drug interaction analysis by HPLC method. High-performance liquid chromatography is a chromatographic technique that can separate a mixture of compounds and is used to identify, quantify and purify the individual components of the mixture. Retention time and absorbance of peak of one species in solution may be changed due to the interaction with other species. In the present study, HPLC analysis of metformin and diclofenac were carried out, using HPLC (Shimadzu, Japan) at pH 7.4 with a concentration of $50 \mu \mathrm{g} / \mathrm{mL}$ where combination of metformin with diclofenac was of 1:1 molar ratio $(50 \mu \mathrm{g} / \mathrm{ml})$. Two operations were carried out.

\section{RESULTS AND DISCUSSION}

In the present study, various methods of analysis were carried out for the determination of drug-drug interaction of metformin with diclofenac. These methods included the spectrophotometric methods of analysis, spectral characteristics, conductometric titrations, Job's method of continuous variations and HPLC. All of these methods of analysis revealed the formation of complexes among the studied drugs.

Absorption spectral observation. The drugs studied showed absorption in UV-VIS region. The molecular species of diclofenac when mixed with metformin, showed some changes in absorption characteristics of this molecule (metformin) including some shifts in the absorption maxima. Thus alteration in spectral pattern may be regarded as an indicator for the primary interaction among these drugs. The UV absorption values of the drug and drug mixtures were measured at 200-400 nm. The spectra of metformin alone at different $\mathrm{pH}$ conditions showed an absorption maximum at $228 \mathrm{~nm} .1 \mathrm{ml}$ of $0.005 \mathrm{M}$ metformin and $1 \mathrm{ml}$ of $0.005 \mathrm{M}$ diclofenac were mixed and absorbance were measured within the range of 200-400 nm. Before that individual absorbance of $0.005 \mathrm{M}$ metformin and diclofenac were measured (Figure 1).

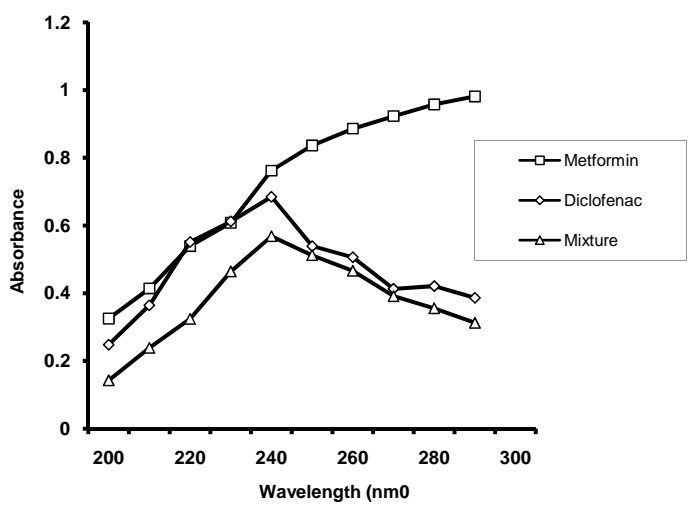

Figure 1. UV spectra of metformin, diclofenac and their mixture at pH 1.4.

$1 \mathrm{ml}$ of $0.005 \mathrm{M}$ metformin and $1 \mathrm{ml}$ of $0.005 \mathrm{M}$ diclofenac were mixed and absorbance were measured within the range of $200-400 \mathrm{~nm}$. Before that individual absorbance of $0.005 \mathrm{M}$ metformin and diclofenac were measured as shown in Figure 2.

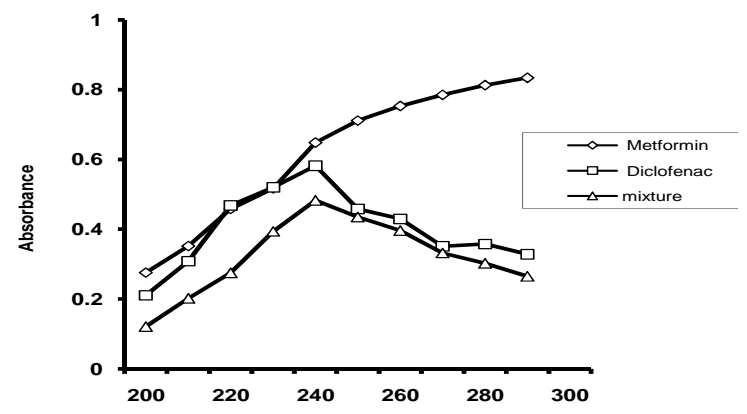

Figure 2. UV spectra of metformin, diclofenac and their mixture at $\mathrm{pH}$ 7.4. 
From the graphs we found that absorbance of individual metformin and diclofenac varied with the absorbance of their combination. It had been seen that the combination graph possessed lower absorbance than the individual. So, from here we could say that 1:1 mixture of metformin and diclofenac resulted into noticeable changes in the absorption intensities due to interaction. The intensities of absorbance peaks also varied with $\mathrm{pH}$. Change in $\mathrm{pH}$ acidic to basic, absorbance shifted to higher wavelength. This ensured that $\mathrm{pH}$ change had significant effects on the interaction between these drugs.

Interaction analysis by Job's method of continuous variations. Job's spectroscopic method of continuous variation was carried out to confirm the formation of 1:1 complexes between the drugs to be studied. Job's plots (Figure 3 and 4 ) gave ' $\Lambda$ ' shaped curve indicating the formation of 1:1 complex for all systems. When metformin was at a very high concentration compared to diclofenac in the mixture, the absorbance decreased larger extent and the difference became negative indicating a stable interaction.

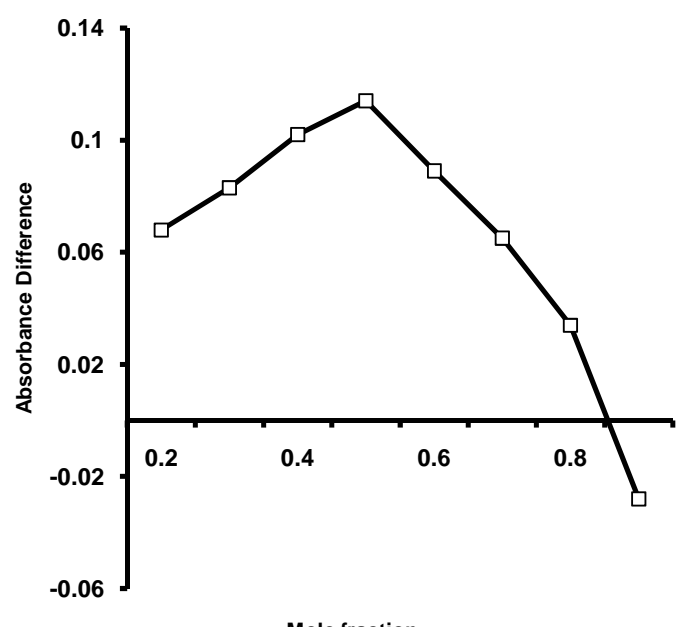

Figure 3. Job's plot for metformin-diclofenac system at pH 7.4.

Conductometric titration. The conductance was plotted versus the molar ratios of the titrants for obtaining conductivity curves (Figure 5).

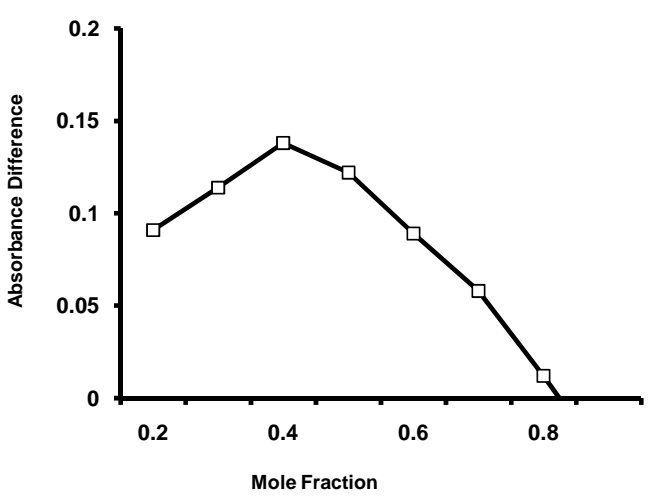

Figure 4. Job's plot for metformin-diclofenac system at $\mathrm{pH} 2.4$.

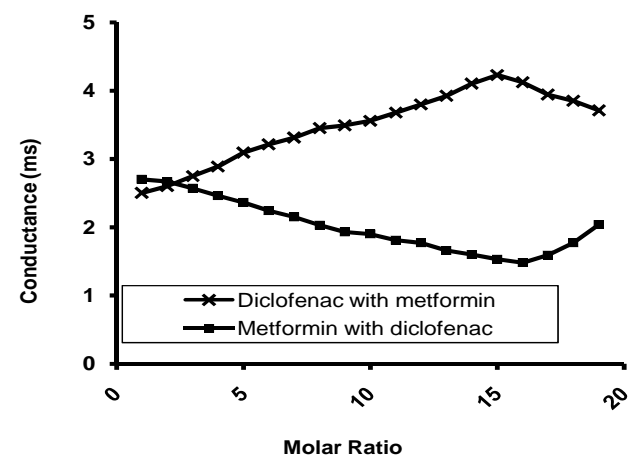

Figure 5. Conductometric titration of metformin with diclofenac at $\mathrm{pH}$ 7.4.

When metformin was titrated with diclofenac at $\mathrm{pH} 7.4$, one distinct intersection corresponding to metformin-diclofenac molar ratios of 1:1 was found in the conductivity curve. The reverse titration showed break at 1:1 molar ratio. These indicated that metformin formed stable complex with diclofenac at 1:1 molar ratio through some unstable complex.

HPLC method for drug interaction analysis. HPLC of metformin: Chromatogram of metformin was taken under following conditions: $10 \%$ acetonitrile, $90 \%$ phosphate buffer, $\mathrm{C}_{8}$ column, flow rate $0.7 \mathrm{ml} / \mathrm{min}, \mathrm{UV} 254 \mathrm{~nm}$, injection volume: $20 \mu \mathrm{l}$. The chromatogram was shown in Figure 6. 


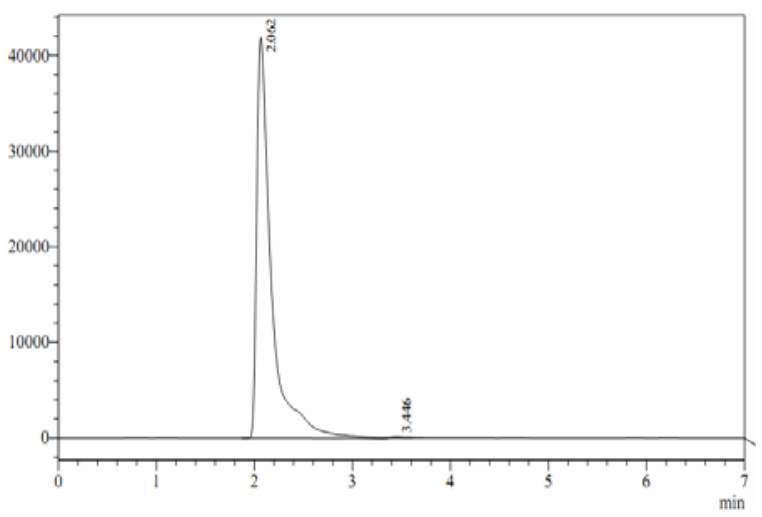

Figure 6. HPLC plot for metformin at $\mathrm{pH}$ 7.4.

HPLC of diclofenac: Chromatogram of diclofenac was taken under following conditions: $70 \%$ acetonitrile, $30 \%$ monobasic sodium phosphate buffer, $\mathrm{C}_{8}$ column, flow rate $0.7 \mathrm{ml} / \mathrm{min}$, UV $278 \mathrm{~nm}$, injection volume: $20 \mu \mathrm{l}$. The chromatogram is shown in Figure 7.

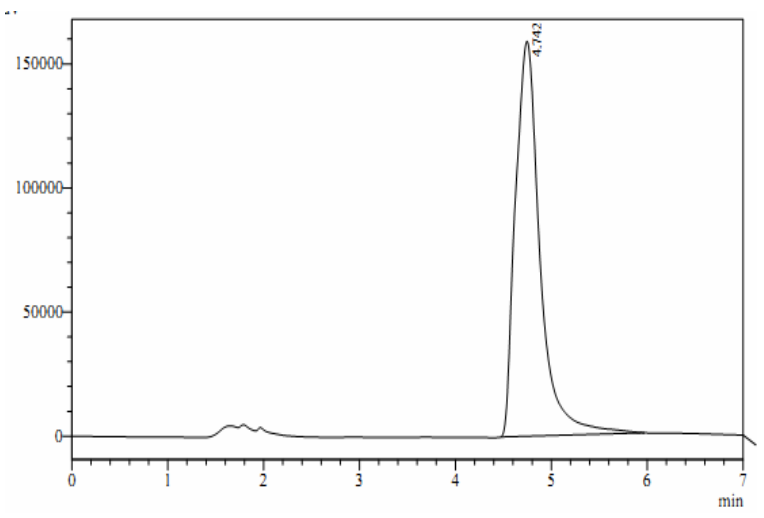

Figure 7. HPLC plot for diclofenac at pH 7.4.

HPLC of diclofenac and metformin: Chromatogram of diclofenac and metformin was taken under following conditions: $90 \%$ phosphate, $10 \%$ acetonitrile for $5 \mathrm{~min}, 10 \%$ to $70 \%$ acetonitrile for $2 \mathrm{~min}, 70 \%$ acetonitrile for $10 \mathrm{~min}, \mathrm{C}_{8}$ column, flow rate $0.7 \mathrm{ml} / \mathrm{min}, \mathrm{UV} 258$ and $278 \mathrm{~nm}$, injection volume: $30 \mu \mathrm{l}$. The chromatogram was shown in Figure 8.

From the aforementioned graph, we found that retention time of metformin alone was $2.062 \mathrm{~min}$ and diclofenac was $4.742 \mathrm{~min}$. But, in case of the combination of metformin with diclofenac $(1: 1)$

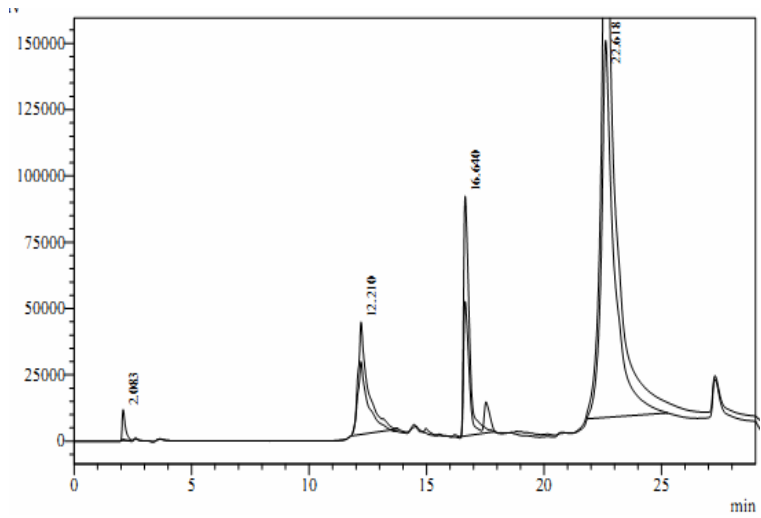

Figure 8. HPLC plot for metformin and diclofenac at $\mathrm{pH}$ 7.4.

retention time shifted to $2.083 \mathrm{~min}$. It was little higher than metformin alone and much lower than diclofenac alone. It indicated a possible interaction between metformin and diclofenac. Moreover, if we observed the graph we found appearance of more peaks at times 12.21, 16.46 and $22.618 \mathrm{~min}$ indicating different species in the mixture. Thus, it could be infared that a good number of combination products might resulted due to interaction of metformin with diclofenac. These results are comparable to some of our previous studies ${ }^{8-11}$ where simultaneous administration of two or more drugs have been discouraged for the safety of the patient because, in our country, clinical monitorings, even in big hospitals, are rarely performed.

\section{CONCLUSION}

In the present work, the studies were performed by various methods including UV-VIS spectrophotometry, conducto-metry and HPLC. The results from all these allowed to conclud that metformin formed stable complex with diclofenac.

\section{ACKNOWLEDGEMENT}

The authors would like to express their gratitude to the authority of Centre for Advanced Research in Sciences (CARS) for their co-operation to carry out some of the experiments in their laboratory. 


\section{REFERENCES}

1. Kristensen, M.B. 1976. Drug interaction and clinical pharmacokinetics, Clin. Pharmacokin. 1, 351-372.

2. Salam, M.A., Baki, M.A., Azam, A.T.M.Z., Amran, M.S., Amjad, F.M., Rokeya, B. and Hossain, M.A. 2009. In vitro and in vivo effects of glipizide and gliclazide on the protein binding, plasma concentration and serum glucose, cholesterol and creatinine levels of ibuprofen. J. Pharmacol. Toxicol. 4, 307-313.

3. Mohiuddin, M., Amran, M.S. and Hossain, M.A. 2009. The in vivo effects of caffeine on the hypoglycemic activity of gliclazide and metformin in healthy rats. Dhaka Univ. J. Pharm. Sci. 8, 47-51.

4. Hansten, P.D. and Horn, J.R. 1989. Drug interactions: Clinical Significance of Drug-drug Interaction, $6^{\text {th }}$ edition, Philadelphia, pp. 5-13.

5. Hardman, J.G. and Lumbard, L.E. 1996. Goodman's and Gilman's The Pharmacological Basis of Therapeutics, $9^{\text {th }}$ edition, pp. 637, 1510.

6. Bates, R.G.1973. Determination of $\mathrm{pH}$, Theory and Practice. 2nd ed. John Wiley \& Sons, Inc., New York, N. Y. 10016, pp. 50-67.
7. Perrin, D.D. and Boyd, D. 1974. Buffer for $\mathrm{pH}$ and metal ion control, Science Papers Back, New York, pp. 44 - 64.

8. Mohiuddin, M., Azam, A.T.M.Z., Amran, M.S. and Hossain, M.A. 2009. In vitro study on the interaction of caffeine with gliclazide and metformin in the aqueous media. $J$. Pharmacol. Toxicol. 4, 194-204.

9. Ahsan, M.R., Sultan, M.Z., Aamjad, F.M., Sultana, S., Baki, M.A., Md. Aslam Hossain, Hossain, M.A. and Amran, S.M. 2011. The study of in vitro and in vivo effect of concurrent administration of paracetamol and zinc on the antibacterial activity of ciprofloxacin. Dhaka Univ. J. Pharm. Sci. 10, 137142.

10. Ahsan, M.R., Sultan, M.Z., Amjad, F.M., Sultana, S., Baki, M.A., Hossain, M.A., Hossain, M.A. and Amran, S.M. 2012. The study of in vitro interaction of ciprofloxacin with paracetamol and zinc in aqueous medium. J. Sci. Res. 4, 701-08.

11. Siraji, F., Azam, A.T.M.Z., Amran, M.S., Islam, J.N., Amjad, F.M. and Hossain, M.A. 2012. In vitro interaction of metronidazole and mebendazole with copper (ii) and chromium (iii) in aqueous media. J. Sci. Res. 4, 173-181. 